\title{
ESTUDO DA OBTENÇÃO DE CERVEJA SUPLEMENTADA COM OLEO DE COCO EM MOSTO DE ALTA DENSIDADE
}

\author{
$\underline{\text { Roquelí Gabriela do Nascimento de Oliveira }}{ }^{1}$; Milenna Santos Silva ${ }^{2}$; Giovani \\ Brandão Mafra de Carvalho ${ }^{3 .}$ \\ 1. Bolsista PROBIC/UEFS, Graduanda em Engenharia de Alimentos, Universidade Estadual de Feira de Santana, e- \\ mail: gabinoli12@hotmail.com \\ 2. Participante do projeto de pesquisa Núcleo de Inovação em Tecnologias de Fermentação, Departamento de \\ Tecnologia, Universidade Estadual de Feira de Santana, e-mail: milasantos.eng@ gmail.com \\ 3. Orientador, Departamento de Tecnologia, Universidade Estadual de Feira de Santana, e-mail: \\ gbmafra@yahoo.com.br
}

PALAVRAS-CHAVE: cerveja; mosto; óleo de coco.

\section{INTRODUÇÃO}

A cerveja é uma bebida produzida através da fermentação do malte, que tem a função de transformar os carboidratos em etanol. Atualmente estima-se que existam mais de 20 mil tipos de cerveja no mundo. Segundo BORTOLI et al (2013) essa variedade ocorre devido a pequenas mudanças no processo de fabricação da cerveja, como o uso de diferentes temperaturas e tempos de cozimento, de condições de maturação e fermentação e o uso de outros ingredientes, além de cevada, lúpulo e água. De acordo BOFFIL et al. (2014) a cevada passa por um processo chamado de maltagem, que é a formação do malte a partir da germinação parcial dos grãos e secagem após o inicio da germinação para interrompê-la.

O malte é usado para a formação do mosto (mistura do malte moído com a água) e a adição de algum complemento, caso necessário. Depois disso é obtido um mosto rico em açúcares. Segundo DRAGONE, MUSSATO, ALMEIDA E SILVA (2007) a utilização de mostos de alta densidade $\left(16\right.$ a $\left.18^{\circ} \mathrm{P}\right)$ tem sido empregada nas cervejarias como uma forma de aumentar o volume de cerveja produzido, sem aumentar as instalações existentes, pois o produto é diluído após a fermentação para obter a cerveja com o teor alcoólico desejado. Devido à alta pressão osmótica e ao aumento dos níveis de etanol, o desempenho da levedura é reduzido e uma forma de melhorá-lo é a suplementação nutricional com ácidos graxos insaturados como ácido oleico, como afirma DRAGONE et al. (2003). O Óleo de Coco é um produto natural que contem acido oleico e está sendo muito bem aceito pelos consumidores, pois estudos têm relatado diversos benefícios causados pela sua ingestão.

Com base no exposto, o presente trabalho teve como objetivo agregar valor nutritivo à cerveja através da suplementação das leveduras, visando difundir ainda mais o óleo de coco (Cocos nucifera L.) amplamente encontrado na região Nordeste com o desenvolvimento de um processo cervejeiro que seja viável economicamente, tornandose mais um incentivo para a inovação tecnológica.

\section{MATERIAL E MÉTODOS}

\subsection{CARACTERIZAÇÃO DO ÓLEO DE COCO}

Óleo de coco COPRA Extra Virgem foi obtido comercialmente para realização de sua caracterização, com o intuito de ser adicionado posteriormente ao mosto. As analises realizadas para a caracterização foram seguindo a metodologia do Instituto Adolfo Lutz (2004). 


\subsubsection{DETERMINAÇÃO DA DENSIDADE}

Foram pesados $10 \mathrm{~g}$ da amostra em capsula de porcelana, previamente tarada. A amostra foi aquecida durante três horas, resfriada em dessecador até a temperatura ambiente. Depois repetimos a operação de aquecimento e resfriamento até o obter o peso constante.

\section{SAPONIFICAÇÃO}

A amostra foi filtrada, pesada (4 a $5 \mathrm{~g}$ ) e foi adicionado $50 \mathrm{~mL}$ da solução alcoólica de $\mathrm{KOH}$. Foi fervida suavemente em um condensador até a completa saponificação da amostra, durante uma hora. Depois foi adicionado $1 \mathrm{~mL}$ do indicador e foi realizada a titulação com solução de acido clorídrico $0,5 \mathrm{M}$ até desaparecer a cor rósea.

\subsubsection{DETREMINAÇÃO DA ACIDEZ}

Foram pipetados $10 \mathrm{~mL}$ da amostra, transferidos para um Erlenmeyer de $125 \mathrm{~mL}$ onde continha $50 \mathrm{~mL}$ de água. Foram adicionadas quatro gotas de fenolftaleína á amostra e titulada com hidróxido de sódio $0,1 \mathrm{M}$, até apresentar coloração rósea.

\subsubsection{DETERMINAÇÃO DO PH}

Foram pesados $10 \mathrm{~g}$ da amostra em um béquer e diluído com $100 \mathrm{~mL}$ de água. Posteriormente foi determinado o $\mathrm{pH}$ com o $\mathrm{pHmetro}$ previamente calibrado, operando de acordo com as instruções do manual do fabricante.

\subsection{PREPARO DO MOSTO}

\subsubsection{LIMPEZA DAS GARRAFAS}

As garrafas Pets foram limpas com ácido peracético $17 \% \mathrm{p} / \mathrm{p}$ por 30 minutos, após esse tempo o ácido foi retirado, as garrafas foram tampadas e reservadas, pois foram utilizadas para condicionar o mosto após o resfriamento.

\subsubsection{MOSTURAÇÃO}

A mosturação foi norteada pela formulação base para 50 litros de cerveja concentração padrão lager, partindo de um mosto de 10 graus platô $\left({ }^{\circ} \mathrm{P}\right)$, fornecida pelo orientador, com as seguintes matérias-primas e suas respectivas quantidades:

- $8,8 \mathrm{Kg}$ de malte de cerveja pilsen (malte Chatean Pilsen $2 \mathrm{RS}$ Belga);

- 43,8 litros de água primária (água mineral de galão ajustada á pH 5,4 e $35^{\circ} \mathrm{C}$ na presença de malte);

- 20,8 litros de água secundária (água mineral ajustada a $75^{\circ} \mathrm{C}$ );

- $11,1 \mathrm{~g}$ de cloreto de cálcio como tamponante da mosturação;

- 8,29 g de lúpulo em Extrator de Amargor (Nugget 30\% A. Alfa);

- 46,07 g lúpulo Pellets de Aroma (Hersbrueker Pellet T-90 4,4\% A.

Alfa);

O processo de mosturação pode ser visualizado no fluxograma a seguir: 


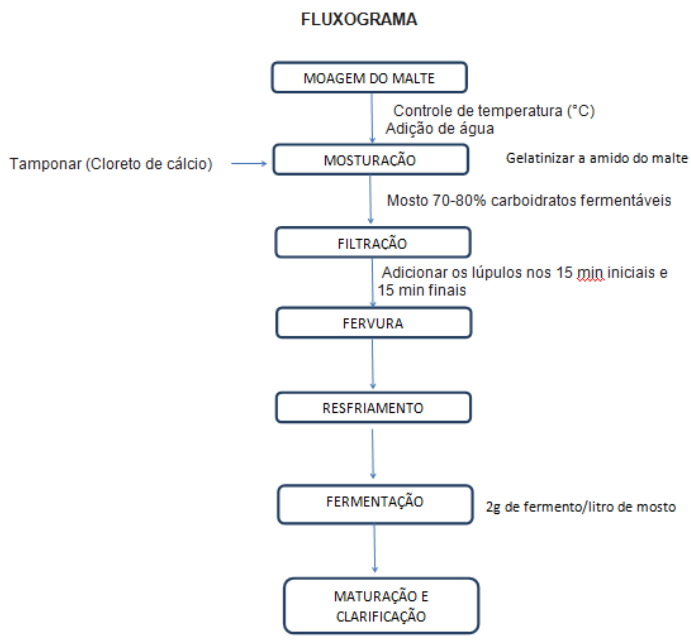

\subsubsection{RAMPA DE TEMPERATURA}

A variação da temperatura é em função do tempo durante o processo de mosturação, seguindo o seguinte parâmetro: $35^{\circ} \mathrm{C}$ á 20 minutos; $45^{\circ} \mathrm{C}$ á 10 minutos; $52^{\circ} \mathrm{C}$ á 10 minutos; $62^{\circ} \mathrm{C}$ á 20 minutos; $72^{\circ} \mathrm{C}$ á 20 minutos; $75^{\circ} \mathrm{C}$ á 05 minutos. Fervura a $100^{\circ} \mathrm{C}$ por 1 hora. Como representado na figura1.

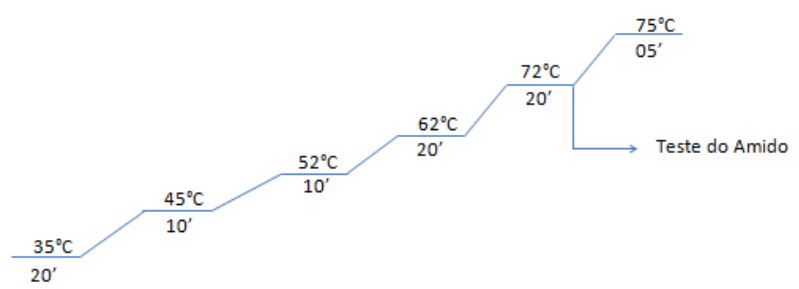

Figura1) Rampa de temperatura. Legenda: ' determina o tempo em minutos.

\subsubsection{TESTE DO AMIDO}

O teste do amido tem por objetivo indicar a sua presença no mosto cervejeiro, pois o amido é formado por moléculas de alto peso molecular (amilopectina e amilose) e essas moléculas podem sofrer reações de complexação, com formação compostos coloridos. Quando esses compostos são misturados com iodo resulta nessa complexação, que pode ser notada pela alteração da cor, como podemos notar na Figura 2.

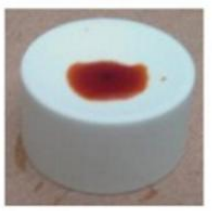

A. lodo puro

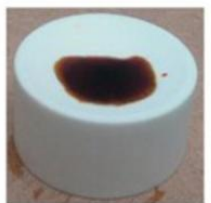

B. lodo+mosto, muito amido (roxo)

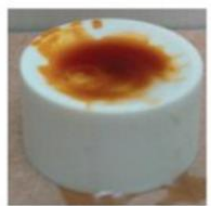

C. lodo+mosto, sem amifolamarel

Figura 2: Resultados do teste do amido. A) O iodo encontra-se puro em sua coloração natural. B) A mistura de iodo e mosto com muito amido resultando numa coloração roxa. C) $\mathrm{O}$ mosto sem amido onde foi adicionado iodo, onde não ouve alteração de cor, pois não havia amido o suficiente para reagir com o iodo. Fonte: $\quad$ LamasBrewShop. Processo Fabricação.http://www.lamasbrewshop.com.br/processo/ 


\section{RESULTADOS E/OU DISCUSSÃO}

O óleo de coco COPRA passou por algumas analises com o intuito de comparar suas características fornecidas no rótulo com as obtidas a partir da metodologia do Instituto Adolfo Lutz (2004). Segue a tabela $1 \mathrm{com}$ os parâmetros e os resultados obtidos.

Tabela1: Comparação das principais características do óleo de coco obtidas no rotulo do produto e resultados obtidos em laboratório.

\begin{tabular}{ccccc} 
Análises & Densidade & $\begin{array}{c}\text { Índice de } \\
\text { saponificação }\end{array}$ & Acidez & pH \\
\hline Parâmetros & 0,897 & 222 & $>0,5$ & - \\
Resultados & 0,872 & 83,03 & 0,3716 & 6,11 á $27,4^{\circ} \mathrm{C}$ \\
\hline
\end{tabular}

O mosto base foi corretamente preparado conforme formulação padrão fornecida pelo orientador. Foi realizado o acompanhamento da rampa de temperatura que é uma fase primordial na preparação do mosto, pois o binômio tempo x temperatura favorece a quebra do amido em açúcares e aminoácidos além da inativação das enzimas. Para verificação destes fatores, o teste do amido foi realizado quando o mosto atingiu a temperatura de $72^{\circ} \mathrm{C}$, não apresentou alteração na cor do mosto, pois não havia amido suficiente para reagir com iodo.

\section{CONSIDERAÇÕES FINAIS}

Foi de suma importância a realização da caracterização do óleo de coco em comparação a descrição do produto comercial e o preparo do mosto base, realizados nesta parte do projeto, pois assim foi possível realizar análises físico-químicas e conhecer a metodologia empregada na mosturação, os ingredientes e a sacarificação completa do amido. O projeto ainda encontra-se em andamento, na fase de suplementação das leveduras durante a fermentação. Sendo assim, outras análises estão sendo realizadas para acompanhamento do projeto, incluindo a contagem de células viáveis com o intuito de analisar as possíveis formas de aumentar a viabilidade celular e a capacidade fermentativa da levedura suplementada pelo óleo de coco.

\section{REFERÊNCIAS}

BOFFILL, Y.; GALLARDO, R.; AGUILAR, I. Ventajas de la producción de cerveza a partir de malta de sorgo. Tecnología Química, v. 34, n. 3, 2014.

BORTOLI, D. A. S et al. Leveduras e produção de cervejas - Revisão. Bioenergia em revista: diálogos, ano 3, n. 1, p. 45-58, 2013.

DRAGONE, G; SILVA, D.P.; ALMEIDA E SILVA, J.B.; LIMA, U.A. Improvement of the etanol productivity in a high gravity brewing at pilot plant scale. Biotechnology Letters, v.25, p. 1171-1174, 2003.

DRAGONE, G; MUSSATO, S. I; ALMEIDA e SILVA, J. B. Utilização de mostos concentrados na produção de cervejas pelo processo contínuo: novas tendências para o aumento da produtividade. Ciência e Tecnologia de Alimentos, v. 27,2007.

INSTITUTO ADOLFO LUTS. Normas Analíticas do Instituto Adolfo Lutz. Métodos Químicos e Físicos para Análise de Alimentos. São Paulo, SP: Secretaria de Estado da Saúde, 1985. p. 46-56.

Processo de Fabricação. LAMAS BREW SHOP Disponível em: http://www.lamasbrewshop.com.br/processo/. Acesso em: 15 jul 2017. 